Ralph Jessen

\title{
Kommune, Attentat, Massenstreik - Arbeiterbewegung, Revolutionsangst und politische Polizei im deutschen Kaiserreich
}

Vom späten 18. Jahrhundert bis zur Gründung des Deutschen Kaiserreiches war die europäische Geschichte eine Zeit revolutionärer Erschütterungen: Angefangen mit der französischen Revolution von 1789 und den Umbrüchen, die sie in den europäischen Gesellschaften und Staaten auslöste, über die revolutionären Erhebungen der 1820er und 1830er Jahre - die griechische Revolution von 1821, die französische Julirevolution von 1830, den polnischen Novemberaufstand von 1830, den blutig niedergeschlagenen Pariser Juniaufstand von 1832 mit 800 Toten - bis zur europäischen Revolutionswelle von 1848/49, die erstmals auch die deutschen Staaten erreichte. Der gescheiterte polnische Aufstand von 1863 gehört ebenso in diesen europäischen Erfahrungszusammenhang wie die Pariser Kommune von $1871 .^{1}$

Wieweit prägte diese Geschichte die politische Kultur des Kaiserreichs? Von Reinhart Koselleck stammt das Begriffspaar von "Erfahrungsraum» und "Erwartungshorizont «. ${ }^{2}$ Der "Erfahrungsraum» der Zeitgenossen dieser Jahrzehnte war zutiefst durch die Revolutionen seit dem ausgehenden 18. Jahrhundert geprägt eine Erfahrung, die wiederum ihren »Erwartungshorizont» beeinflusste, sei es po-

\footnotetext{
1 Vgl. Bergeron, Louis/ Furet, François/ Koselleck, Reinhart: Das Zeitalter der europäischen Revolution 1780 - 1848, Frankfurt/M. 1969; von Hippel, Wolfgang/ Stier, Bernhard: Europa zwischen Reform und Revolution 1800-1850, Stuttgart 2012; Hobsbawm, Eric J.: Europäische Revolutionen, München 1962; Fahrmeir, Andreas: Revolutionen und Reformen. Europa 1789-1850. München 2010; Hahn, Hans-Werner/ Berding, Helmut: Reformen, Restauration und Revolution 1806 -1848/49, Stuttgart 2010; Langwiesche, Dieter: Europa zwischen Restauration und Revolution 1815-1849, 5. Aufl., München 2007; Ruttmann, Ulrike: Wunschbild - Schreckbild - Trugbild. Rezeption und Instrumentalisierung Frankreichs in der deutschen Revolution von 1848/49, Stuttgart 2001; Sperber, Jonathan: Revolutionary Europe, 1780 1850, Harlow 2000.

2 Koselleck, Reinhart: Erfahrungsraum und Erwartungshorizont - zwei historische Kategorien, in: Vergangene Zukunft. Zur Semantik geschichtlicher Zeiten, hrsg. von Reinhart Koselleck, 3. Aufl., Frankfurt 1984, S. $349-375$.
} 
sitiv als Revolutionshoffnung oder negativ als Revolutionsfurcht. Die Vorstellung einer latenten, sich möglicherweise in naher Zukunft aktualisierenden Bedrohung der politischen Ordnung durch eine neue Revolution, die sich in ein seit 1789 andauerndes Zeitalter der Revolution einfügte, war Anfang der 1870er Jahre vielen bürgerlichen Beobachtern vertraut. Der Historiker Jacob Burckhardt meinte 1871, „dass eigentlich Alles bis auf unsere Tage im Grunde lauter Revolutionszeitalter ist, und wir stehen vielleicht erst relativ an den Anfängen oder im zweiten Akt; denn jene drei scheinbar ruhigen Dezennien von 1815 bis 1848 haben sich zu erkennen gegeben als einen bloßen Zwischenakt in dem großen Drama. Dieses aber scheint eine Bewegung werden zu wollen. ${ }^{3}$

\section{Revolutionserwartung und Revolutionsangst im frühen Kaiserreich}

Vor allem der Aufstand der Pariser Kommune, der durch die französische Niederlage im deutsch-französischen Krieg von 1870/71 ausgelöst worden war, ist im gerade gegründeten deutschen Kaiserreich intensiv wahrgenommen worden. Die Pariser Erhebung und die Gewaltexzesse bei ihrer Niederschlagung aktualisierten die Revolutionserfahrung der zurückliegenden Jahrzehnte auf dramatische Weise. "Der lange Schatten der Kommune ${ }^{4}$ wurde zum Ausgangspunkt sowohl für eine positive Mystifikation der Revolution in der entstehenden sozialistischen deutschen Arbeiterbewegung, wie für deren negative, antirevolutionäre Mystifikation als ein Schreckbild, das die Revolutionsfurcht der Regierenden bestätigte und sich als propagandistische Waffe gegen die sozialistische Arbeiterbewegung eignete.

In der frühen Sozialdemokratie der 1860er und frühen 1870er Jahre lebte ohnehin die Erinnerung an die Revolution von 1848/49 weiter und war Ausgangspunkt populärer Revolutionserwartungen, was wiederum bei staatlichen Behörden und bürgerlichen Beobachtern »alte Revolutionsängste» weckte. ${ }^{5}$ Man betonte die eigene Gesetzlichkeit, lebte aber auch mit der Vorstellung, dass ein revolutionärer Umbruch in der Verlängerung von 1789/1848/1871 nicht nur möglich, sondern

3 Burkhardt, Jacob: Gesamtausgabe Bd. 7, S. 426, zitiert nach: Pöls, Werner: Sozialistenfrage und Revolutionsfurcht in ihrem Zusammenhang mit den angeblichen Staatsstreichplänen Bismarcks, Lübeck 1960, S. 27 f. Amerigo Caruso spricht in seiner vergleichenden Analyse der Frühgeschichte des Konservativismus in Deutschland und Italien von einer »obssesive(n) Präsenz der Revolutionsangst in den europäischen Politikdiskursen«. Caruso, Amerigo: Nationalstaat als Telos? Der konservative Diskurs in Preußen und Sardinien-Piemont 1840 - 1870, München 2017, S. 52.

4 von Münchhausen, Thankmar: 72 Tage. Die Pariser Kommune 1871 - die erste »Diktatur des Proletariats«, München 2015, S. 447.

5 Schmidt, Jürgen: Brüder, Bürger und Genossen, Die deutsche Arbeiterbewegung zwischen Klassenkampf und Bürgergesellschaft 1830-1870, Bonn 2018, S. 363. 
auch wahrscheinlich und letztlich auch wünschenswert wäre. Eine Massenerhebung des Volkes à la 1848 sollte eine demokratische Verfassung an die Stelle illegitimer Fürstenherrschaft setzen, die Einheit der Nation herstellen und den Weg zu einer tiefgreifenden sozialen Umgestaltung der Gesellschaft ebnen. In den frühen 1870er Jahren wurde in sozialdemokratischen "Märzfeiern" an die glorreichen Tage der 48er Revolution erinnert und die jüngste Erfahrung der Pariser Kommune inspirierte Hoffnungen auf eine bald kommende Revolution: Wilhelm Hasenclever meinte auf einer »Märzfeier» im Jahr 1874, „daß alle großen Ideen erst durch das Blut ihrer Träger und durch gewaltsame Umwälzungen besiegelt seien. Die Berliner Revolution von 1848 sei mehr das letzte blutige Zucken des großen Gewitters von 1789-1793 gewesen, während die Pariser Revolution von 1848 und vor allem der Communekampf von 1871 das Wetterleuchten einer großen Zukunft bedeuteten. ${ }^{6}$ Mit dieser Prognose stand er nicht allein. Auch Karl Marx hat mit Blick auf die Kommune gemeint, dass »die französischen Arbeiter [...] nur die Vorhut des ganzen modernen Proletariats [bilden]. «7 Die größte öffentliche Wirkung hatte vermutlich der sozialdemokratische Parteiführer und Reichstagsabgeordnete August Bebel, der am 25. Mai 1871 im Reichstag unter dem unmittelbaren Eindruck der Ereignisse ausrief, „daß der Kampf in Paris nur ein kleines Vorpostengefecht ist, daß die Hauptsache in Europa uns noch bevorsteht, und daß, ehe wenige Jahrzehnte vergehen, der Schlachtruf des Pariser Proletariats: ১Krieg den Palästen, Friede den Hütten, Tod der Noth und dem Müßiggange!ı der Schlachtruf des gesammten europäischen Proletariats werden wird. ${ }^{8}$

Bei dem Feuerkopf Johann Most, der sich später von der Sozialdemokratie abwandte und vom amerikanischen Exil aus als wortgewaltiger Verfechter des Anarchismus nach Deutschland hineinwirkte, bekam diese Revolutionserwartung eine geradezu eschatologische Dimension. 1872 prognostizierte er in einer Rede:

"Ja, die Sündfluth wird kommen. Ein furchtbares Ungewitter wird wie ein Sturm dahin fegen und diejenigen auskehren, die sich ihm in den Weg stellen. [...] Wir [Sozialdemokraten] haben die Sache nicht in der Hand; wir können darüber nicht entscheiden, ob auf dem Wege der Reform oder der Revolution unsere Principien verwirklicht werden können - das haben unsere Gegner in der Hand. [...] Werden sie sich [...] dieser Bewegung entgegenstemmen, dann wird es ihnen gehen, wie den Leuten, die einen Sturm aufhalten wollten. Und es wird dieser Sturm der Zeit aus seinen Ufern treten und wird alles überschwemmen." ${ }^{9}$

$6 \quad$ Neuer Social-Demokrat, Nr. 34, 22.3.1874.

7 Marx, Karl: Der Bürgerkrieg in Frankreich. Adresse des Generalrats der Internationalen Arbeiterassoziation, in: Karl Marx. Friedrich Engels. Werke, Band 17, 5. Aufl., Berlin 1973, S. 313 - 365, hier S. 361.

$8 \quad$ Protokolle des Deutschen Reichstags, 1. Legislaturperiode, 43. Sitzung am 25. Mai 1871, S. 921.

9 Zitat nach Welskopp, Thomas: Das Banner der Brüderlichkeit. Die deutsche Sozialdemokratie vom Vormärz bis zum Sozialistengesetz, Bonn 2000, S. 526. 
Solche alttestamentarisch apokalyptische Rhetorik versorgte die Anhängerschaft der jungen Arbeiterbewegung mit einer positiven Zukunftsvision und deren Gegner mit propagandistischer Munition, um die Sozialdemokratie als revolutionäre Bedrohung der politischen und sozialen Ordnung auszugrenzen. Dabei ließ sich ausgerechnet in der Most'schen Eschatologie ein Revolutionsverständnis erkennen, das sich während der folgenden Jahrzehnte in der deutschen Sozialdemokratie immer stärker durchsetzen sollte: Revolution war nicht etwas, was aktiv angestrebt, betrieben und "gemacht" werden musste, sondern ein zu erwartendes Ereignis, das mit geradezu naturgesetzlicher Notwendigkeit die bestehenden Verhältnisse umwälzen würde.

\section{Die politische Polizei}

Die "Ordnungsmächte» setzten seit der Ära Metternich darauf, die republikanischen und demokratischen Bestrebungen sowie die Anfänge der sozialistischen Arbeiterbewegung als potentiell revolutionäre Kräfte scharf zu kontrollieren und im Zweifelsfall zu unterdrücken. Dies war Aufgabe der "höheren Polizei«, die seit den 1830er Jahren komplementär zur schrittweisen Institutionalisierung einer neuen politischen Öffentlichkeit gegründet und aufgebaut wurde. Die Anfänge einer koordinierten politisch-polizeilichen Überwachung der Öffentlichkeit im "Mainzer Informations-Bureau“ $(1833-1848)^{10}$ fanden in den 1850er Jahren ihre Fortsetzung im »Polizeiverein der bedeutenderen deutschen Staaten«, der auf preußische Initiative gegründet worden war und bis 1866 bestand. Dieser informelle Zusammenschluss führender Polizeibeamten aus den Haupt- und Residenzstädten von sieben deutschen Staaten sollte durch den Informationsaustausch auf regelmäßigen Konferenzen und die Zirkulation schriftlicher Dossiers die »Umtriebe der Revolutionspartei« im Blick und unter Kontrolle halten. Vor allem in den ersten Jahren nach der 48er Revolution waren die Mitglieder des »Polizeivereins" auf die "traumatische Konstellation von Konspiration, internationaler Revolution und Fürstenmord» fixiert, wie Wolfram Siemann, der hierzu die einschlägigen Forschungen vorgelegt hat, pointiert zusammenfasst. ${ }^{11}$ Arbeitsweise und

10 Adler, Hans: Staatsschutz im Vormärz, in: Literarische Geheimberichte. Protokolle der MetternichAgenten, Bd. I: 1840 - 1843, hrsg. von Hans Adler, Köln 1977, S. 1-45; vgl. auch Weidemann, Friedrich: Über die Nothwendigkeit einer geheimen Polizei in Deutschland. Eine Staatswissenschaftliche Abhandlung, Merseburg 1832.

11 Siemann, Wolfram: Der »Polizeiverein« deutscher Staaten. Eine Dokumentation zur Überwachung der Öffentlichkeit nach der Revolution von 1848/49, Tübingen 1983, S. 239. Ein Überblick über die Genese des Polizeivereins ebd., S. 1-19. Zur Geschichte der Polizei in der ersten Hälfte des 19. Jahrhunderts immer noch grundlegend: Lüdtke, Alf: „Gemeinwohl«, Polizei und »Festungspraxis». Staatliche Gewalt- 
Ziel der politischen Polizei waren bis in die 1860er von einem Feindbild geprägt, das um die Vorstellung einer zentral gesteuerten, international verflochtenen, im Geheimen operierenden revolutionären Konspiration kreiste. Wusste man genug über die führenden Köpfe dieser Bewegung, so die strategische Prämisse, war man in der Lage, deren Pläne zu durchkreuzen. ${ }^{12}$

Nach der Reichsgründung liefen trotz der föderalen Struktur des Reiches und der Polizeizuständigkeiten der einzelnen Staaten de facto immer mehr Kompetenzen und Kapazitäten zur Überwachung mutmaßlicher "Reichsfeinde» bei der preußischen Polizei und vor allem bei der Berliner Polizeibehörde zusammen. Nach dem Verbot der sozialdemokratischen Partei durch das Sozialistengesetz von 1878 wurde die Berliner Politische Polizei zur zentralen politischen Überwachungsinstitution in Preußen, und bis zu einem gewissen Grade des Reiches, ausgebaut. Im September 1878 umfasste sie 148 Beamte. In kurzer Zeit hatten sich ihr Personalbestand verfünffacht und die ihr zur Verfügung stehenden Mittel versechsfacht. Ihre Hauptaufgabe war die Überwachung aller Aktivitäten der Sozialdemokraten und Anarchisten: Die Beobachtung von Versammlungen, die Kontrolle von Reisenden und Gasthöfen, die Observation bekannter Agitatoren und einschlägiger Lokale. ${ }^{13}$

Treibende Kraft des Polizeiausbaus war der Berliner Polizeipräsident Guido von Madai. Sein Feindbild glich in vielem den Imaginationen, die schon die Aktivitäten des postrevolutionären Polizeivereins der 1850er Jahre angetrieben hatten. Am 25. Juli 1878, keine zwei Monate nach dem gescheiterten Attentat auf den Kaiser, das zur Begründung des Sozialistengesetzes diente, notierte von Madai in einem geheimen Bericht, man habe es nicht allein mit den deutschen Sozialisten zu tun, sondern mit einer »internationalen revolutionären Liga». Diese »Internationale» arbeite »streng diszipliniert, einheitlich geleitet und unbedingt einem Haupte gehorchend" und sei in Deutschland, England, Frankreich, der Schweiz, Belgien und Österreich-Ungarn aktiv:

samkeit und innere Verwaltung in Preußen (1815-1850), Göttingen 1982. Zur polizeilichen Kontrolle der Öffentlichkeit in der ersten Hälfte des 19. Jahrhunderts auch: Riesener, Dirk: Polizei und politische Kultur im 19. Jahrhundert. Die Polizeidirektion Hannover und die politische Öffentlichkeit im Königreich Hannover, Hannover 1996.

12 Jessen, Ralph: Polizei im Industrierevier. Modernisierung und Herrschaftspraxis im westfälischen Ruhrgebiet 1848 - 1914, Göttingen 1991, S. 39; Langewiesche, Dieter: „Staatsschutz« und politisch-gesellschaftlicher Wandel in Deutschland 1848 -1914, in: Literarische Geheimberichte. Protokolle der Metternich-Agenten, Bd. II: 1844 - 1848, hrsg. von Hans Adler, Köln 1981, S. 201-233.

13 Fricke, Dieter: Bismarcks Prätorianer. Die Berliner Politische Polizei im Kampf gegen die deutsche Arbeiterbewegung (1871-1898), Berlin 1962, S. 54 f. Vgl. auch Wilms, Reinhard: Politische Polizei und Sozialdemokratie im Deutschen Kaiserreich. Zur Tätigkeit der Politischen Polizei in der Provinz Hannover von der Zeit der Reichsgründung bis zum Ende des Sozialistengesetzes 1871-1890, Frankfurt 1992; Evans, Richard J. (Hrsg.): Kneipengespräche im Kaiserreich. Die Stimmungsberichte der Hamburger Politischen Polizei. 1892 - 1914, Reinbek b. Hamburg 1989. 
»Ihre Pläne sind die denkbar weitgehendsten. Sie binden sich weder an Ort, Raum, Entfernung oder Staat, sie haben eine vollständig universelle Natur. Hierzu kommt die Bewegung ihrer Mitglieder, die bald hier, bald dort, bald unter diesem, bald unter jenem Namen auftauchen und wieder verschwinden und denen Reisen von Hunderten von Meilen völlig irrelevant erscheinen. Dieser Verbindung, welche auch unzweifelhaft mit Geldmitteln reich versehen ist, steht das Polizeipräsidium beinahe machtlos gegenüber, ja es ist nicht ausgeschlossen, daß ihre Pläne geradezu unter den Augen der Polizei hier in Berlin gefaßt werden. «14

Dass er es mit einer großangelegten internationalen revolutionären Verschwörung zu tun hatte, stand für von Madai außer Frage. Man fühlt sich bei seinen Ausführungen an den Eröffnungssatz des Kommunistischen Manifests von 1848 erinnert: "Ein Gespenst geht um in Europa, das Gespenst des Kommunismus." Und so wie Marx und Engels die Bedeutung der kleinen kommunistischen Sekten ihrer Zeit maßlos überschätzten, so realitätsfern wirkt auch von Madais Phantasmagorie einer geisterhaften revolutionären Verschwörung, deren Angehörige nach Belieben Identitäten und Räume wechseln. ${ }^{15}$

Auch wenn diese Feindbilder wenig mit der Realität zu tun hatten, legitimierten sie doch den Aufbau eines geheimpolizeilichen Beobachtungssystems und Berichtswesens. Zwar ließ sich von Madais Idee eines umfassenden Agentennetzes in den europäischen Metropolen und den wichtigsten deutschen Städten nur teilweise realisieren. ${ }^{16}$ Aber zusammen mit den regelmäßigen Berichten der preußischen Regierungspräsidenten lieferten die von den Agenten beschafften Informationen eine hinreichend breite Faktenbasis, um den Innenbehörden einen kontinuierlichen Einblick in den Stand und die Entwicklung der fundamentaloppositionellen politischen Bewegungen zu geben. Aus diesen Informationen kompilierte das Berliner Polizeipräsidium zusammenfassende Lageanalysen, die anfangs halbjährlich, später jährlich als geheime Hintergrundinformationen an rund 150 höhere Beamte und Dienststellen im In- und Ausland gingen. ${ }^{17}$ Bis 1913 entstanden so 34 Berichte, die zunächst als "Übersichten über die allgemeine Lage der sozialdemokratischen und revolutionären Bewegung«, ab 1898 als „Übersichten über die allgemeine Lage der sozialdemokratischen und anarchistischen Bewegung « firmierten. ${ }^{18}$

14 Bericht vom 25. 7.1878, zitiert nach Fricke, Prätorianer, S. 51.

15 Vgl. Roller, Kathrin: Die »rote Gefahr«. Das Feindbild »Sozialdemokratie» der Konservativen im frühen Kaiserreich, in: Feindbilder in der deutschen Geschichte, hrsg. von Christoph Jahr, Berlin 1994, S. $81-114$.

16 Fricke, Prätorianer, S. 52.

17 Ebd. S. XI.

18 Fricke, Dieter/ Knaack, Rudolf (Hrsg.): Dokumente aus geheimen Archiven. Übersichten der Berliner politischen Polizei über die allgemeine Lage der sozialdemokratischen und anarchistischen Bewegung 1878-1913, Bd.1: 1878-1889, Weimar 1983; Bd. 2: $1890-1906$, Weimar 1989; Bd. 3: $1906-$ 1913, Berlin 2004. 


\section{Politischer Radikalismus und proletarische Protestkultur}

Die kollektive Revolutionserinnerung und die populäre, wenn auch diffuse, eschatologisch verbrämte und kaum mit einer entsprechenden Praxis verbundene Revolutionserwartung in der jungen Arbeiterbewegung bildeten den wichtigsten Anlass für die Revolutionsfurcht in Regierungskreisen und bei den Polizeichefs der deutschen Staaten. Hinzu kam ein weiterer Faktor, der eher etwas mit dem Habitus der Arbeiteraktivisten der 1860er und 1870er Jahre zu tun hat. Thomas Welskopp hat diese Haltung in seiner Studie zur Frühgeschichte der Sozialdemokratie ausführlich geschildert und analysiert: Die sozialdemokratische Vereinsund Versammlungspraxis bezog ihre Attraktion nicht nur aus politischen Forderungen nach Anerkennung, Demokratie und sozialer Gerechtigkeit, sondern auch aus der Inszenierung einer »kampfbereiten Männlichkeit«. ${ }^{19}$ Die Versammlungsöffentlichkeit der 1860er und 1870er Jahre, in der sich die verschiedenen sozialdemokratische Richtungen einerseits von den bürgerlichen Liberalen absetzten und andererseits miteinander konkurrierten, lebte weniger vom disziplinierten Austausch politischer Argumente, als von der demonstrativen, bald ernsthaften, bald spielerisch-ironischen Inszenierung des politischen Kampfes. Zwar legte man im Allgemeinen Wert darauf, als seriöse, die Regeln der parlamentarischen Debatte beachtende Repräsentanten des Volkes anerkannt zu werden. Nicht selten aber eskalierten die Zusammenstöße mit dem politischen Gegner, gingen Versammlungsdebatten in Tumulte und manchmal in Saalschlachten über: Von einer ADAV-Versammlung in Glückstadt wurde 1871 berichtet: "Alsbald ertönte im mächtigen Chor die Marseillaise. Bleich und voll Angst standen die Gegner da, und als sie den festen Zusammenhalt der Unseren sahen, ergriffen sie Hals über Kopf die Flucht. ${ }^{20}$ Skandal, Tumult und Leidenschaft waren die Würze mancher Arbeiterversammlung und wenn es besonders hoch her ging, konnte es auch zum Zusammenstoß mit der Obrigkeit kommen. Als im Frühjahr 1869 der überwachende Polizeikommissar eine Sitzung des Lassaleschen ADAV in Mönchengladbach auflösen wollte, kam es zu einer Schlägerei, die "nicht unbedeutende Verwundungen mehrerer herbeigeeilter Gensd'armen und Polizisten durch Messerstiche, resp. Schläge mit Biergläsern zur Folge hatte." Und weiter hieß es in dem Bericht: „Nach erzwungener Räumung des Lokales setzte die zu Tausenden angewachsene Menge die begonnenen Exzesse durch Einwerfen von Fensterscheiben $[. .$.$] in der Weise fort, daß die hiesigen Behörden sich veranlaßt sahen,$ [...] militärische Hilfe von dem Regierungs-Präsidenten in Düsseldorf zu requiri-

19 Welskopp, Banner, S. 335.

20 Neuer Social-Demokrat, Nr. 7, 16. 7.1871, zitiert nach Welskopp, Banner, S. 314. 
ren. Letzterer Requisition wurde jedoch nicht entsprochen. ${ }^{21}$ Solche Begebenheiten erinnern an ältere Formen des Volksprotests und der "Pöbelexzesse», die in der Pauperismuskrise des Vormärz häufiger zu sehen waren, aber auch in der zweiten Hälfte des 19. Jahrhunderts durchaus noch Bedeutung hatten, vor allem in den großstädtischen Unterschichten.22 Aus Sicht der bürgerlichen und obrigkeitlichen Beobachter zeigte sich bei solchen Gelegenheiten die "gefährliche Klasse«, die durch mangelnde Selbstbeherrschung, zweifelhafte Moral, Alkoholexzesse und die Neigung zur Gewalt die öffentliche Ordnung herausforderte. ${ }^{23} \mathrm{Je}$ mehr sich die Sozialdemokratische Partei und die vielen Arbeitervereine im letzten Drittel des 19. Jahrhunderts zu Ordnungsmächten eigener Art entwickelten, desto mehr geriet diese "wilde» Seite des proletarischen Männlichkeitskults zwar an den Rand der Arbeiterbewegung. In der Frühzeit war diese Trennlinie aber noch nicht scharf gezogen, so dass sich die Angst vor dem politischen Umsturz und die vor der Auflösung bürgerlicher Ordnung im Syndrom der "Revolutionsfurcht» verbinden konnten. ${ }^{24}$

\section{Revolutionsangst und Sozialistengesetz}

Aus dieser widersprüchlichen Ausgangskonstellation heraus entwickelte sich die sozialdemokratische Arbeiterbewegung und konsolidierte sich 1875 mit dem Zusammenschluss der Eisenacher Richtung und der Lassalleaner zur Sozialistischen Arbeiterpartei Deutschlands. Aufgrund des allgemeinen, gleichen Männerwahlrechts war die Partei von Anfang an im Reichstag vertreten und konnte einen wachsenden Wähleranhang verzeichnen - ein Faktor, der nicht wenig zu ihrer öffentlichen Wahrnehmung beitrug. Die Reichsregierung unter Kanzler Bismarck hat die sozialdemokratische Arbeiterbewegung bekanntlich mit großem Misstrauen betrachtet und sich in mehreren Anläufen bemüht, ihren Handlungsspiel-

21 Demokratisches Wochenblatt, Nr. 18, 1.5.1869, S. 200 f., zitiert nach Welskopp, Banner, S. 322.

22 Gailus, Manfred (Hrsg.): Pöbelexzesse und Volkstumulte in Berlin. Zur Sozialgeschichte der Straße (1830 - 1980), Berlin 1984. Vgl. auch Kocka, Jürgen/ Jessen, Ralph: Die abnehmende Gewaltsamkeit sozialer Proteste. Vom 18. zum 20. Jahrhundert, in: Verdeckte Gewalt. Plädoyers für eine »innere Abrüstung", hrsg. von Peter-Alexis Albrecht/ Otto Backes, Frankfurt 1990, S. 33 - 56; Jessen, Ralph: Gewaltkriminalität im Ruhrgebiet zwischen bürgerlicher Panik und proletarischer Subkultur (1870 - 1914), in: Kirmes Kneipe - Kino. Arbeiterkultur im Ruhrgebiet zwischen Kommerz und Kontrolle (1850-1914), hrsg. von Dagmar Kift, Paderborn 1992, S. 226-255.

23 Sobich, Frank Oliver: "Schwarze Bestien, rote Gefahr». Rassismus und Antisozialismus im deutschen Kaiserreich, Frankfurt/M. 2006, S. 157-163.

24 Das lässt sich auch an der nachträglichen Deutung der Pariser Kommune durch die Untersuchungsausschüsse der Französischen Nationalversammlung erkennen, die die Aufständischen als Mörder, Brandstifter, Plünderer, Säufer und Tagediebe stigmatisierten. Münchhausen, Kommune, S. 449. Vgl. auch Sobich, Bestien, S. $152 \mathrm{ff}$. 
raum zu beschränken, die Bewegung zu marginalisieren und die Partei letztlich zu unterdrücken. ${ }^{25}$ Ein erster Versuch, die radikale Opposition durch ein restriktives Pressegesetz mundtot zu machen, scheiterte 1874 an den Liberalen. Ein zweiter Anlauf, diesmal über eine Verschärfung des Strafgesetzbuches, durch die die "Aufreizung zum Klassenhass" unter Strafe gestellt werden sollte, fand ebenfalls keine Mehrheit im Reichstag. Das Blatt wendete sich schließlich 1878, nachdem zwei Attentate auf den Kaiser, die fälschlicherweise den Sozialdemokraten zugerechnet wurden, die nötige Stimmung und eine Reichstagsneuwahl die nötige Mehrheit erbracht hatten. ${ }^{26}$ Das "Gesetz gegen die gemeingefährlichen Bestrebungen der Sozialdemokratie» - das "Sozialistengesetz" von 1878, das bis 1890 in Kraft blieb - ermöglichte das Verbot aller sozialdemokratischen Vereine, Versammlungen und Publikationen. Lediglich das Reichstagswahlrecht blieb unverändert und sicherte den Sozialdemokraten ihre Präsenz im Parlament. Die Kampagne gegen die «roten Reichsfeinde» wurde mit schriller Rhetorik geführt: Das Ausnahmegesetz sei erforderlich zur »Rettung der Gesellschaft vor Mördern und Mordbrennern, vor den Erlebnissen der Pariser Commune», so Bismarck 1878, und an anderer Stelle hieß es: "Die jährliche Vermehrung der bedrohlichen Räuberbande, mit der wir gemeinsam unsere größeren Städte bewohnen, [...] [erzwinge die] Solidarität der Notwehr.« ${ }^{27}$ Bereits im Mai 1871, als August Bebel im Reichstag die Pariser Kommune verteidigt hatte, sei ihm klar geworden, dass die Sozialdemokraten der innere Feind seien, gegenüber dem sich der Staat im "Zustand der Notwehr befinde.« ${ }^{28}$ Das Menetekel des Pariser Aufstands war sieben Jahre nach den Ereignissen noch präsent. ${ }^{29}$

Die Frage, ob dies Ausdruck einer ernstzunehmenden Revolutionsfurcht oder demagogischer Stimmungsmache war, ist in der Bismarck- und Kaiserreichforschung immer wieder kontrovers diskutiert worden. Werner Pöls hat in seiner frühen Arbeit zu "Sozialistenfrage und Revolutionsfurcht» von 1960 betont, dass Bismarck und die Reichstagsmehrheit von einer ernst zu nehmenden Angst vor der Revolution getrieben worden seien, die zwar keine reale Grundlage im Handeln der Sozialdemokraten gehabt habe, aber eine subjektiv authentische Bedro-

25 Zum obrigkeitlichen Vorgehen gegen die frühe Arbeiterbewegung vgl. aus regionalhistorischer Perspektive Schäfer, Markus: Staatliches Vorgehen gegen Arbeiterbewegungen und -organisationen im westlichen Ruhrgebiet zwischen Revolution und Sozialistengesetz (1850-1878), Trier 2006.

26 Mühlnikel, Marcus: „Fürst, sind Sie unverletzt?« Attentate im Kaiserreich 1871-1914, Paderborn 2014 , S. $33-67$.

27 Zitiert nach Wehler, Hans-Ulrich: Deutsche Gesellschaftsgeschichte. Bd. 3: Von der iDeutschen Doppelrevolution` bis zum Beginn des Ersten Weltkrieges. 1849-1914, München 1995, S. 904 f.

28 Zitiert nach Pöls, Sozialistenfrage, S. $29 \mathrm{f}$.

29 Vgl. auch Mühlhausen, Walter: Gegen den Reichsfeind. Anmerkungen zur Politik von Staat und Gesellschaft gegenüber der Sozialdemokratie im Kaiserreich, in: Otto von Bismarck und das "lange 19. Jahrhundert». Lebendige Vergangenheit im Spiegel der "Friedrichsruher Beiträge» 1996 - 2016, hrsg. von Ulrich Lappenküper, Paderborn 2017, S. 329-352. 
hungswahrnehmung gewesen sei.30 Die Politik gegenüber der Sozialdemokratie sei in den 1870er und 1880er Jahren "von einer bis zur Revolutionsüberzeugung gesteigerten Revolutionsfurcht» bestimmt gewesen. ${ }^{31}$ Der ostdeutsche Historiker Dieter Fricke sah in der Unterdrückungspolitik dagegen ein Zeichen brutaler Klassenherrschaft und warf Pöls »eine psychologisierende Überbetonung der `Revolutionsfurcht» Bismarcks" vor. ${ }^{32}$ Viel Beachtung hat in den 1970er und 1980er Jahren eine Deutung gefunden, die besonderes pointiert von Hans-Ulrich Wehler in seinem vielgelesenen Kaiserreichsbuch vertreten worden ist. Er, aber auch andere Historiker wie Dieter $\mathrm{Groh}^{33}$, sahen im Sozialistengesetz wie schon im Kulturkampf vor allem eine kühl umgesetzte Herrschaftstechnik der »negativen Integration", die darauf beruhte, die Mehrheit der Kaiserreichsgesellschaft und der "reichstreuen" Parteien durch ein möglichst dramatisch gezeichnetes Feindbild zusammenzuscharen. ${ }^{34}$ Der amerikanische Historiker Otto Pflanze hat dies in seinen Bismarckstudien in den 1980er Jahren zurückgewiesen: „Dem Kulturkampf vergleichbar, hatte auch die antisozialistische Kampagne der Jahre 1878 bis 1890 den Charakter eines innerdeutschen `Präventivkrieges`. Die Furcht vor einer unsicheren Zukunft, die Kulturkampf und Sozialistengesetzgebung auslöste, war fraglos echt, nicht simuliert. «35 Der späte Wehler scheint sich auch eher in diese Richtung bewegt zu haben: Von "negativer Integration" ist in seiner großen Gesellschaftsgeschichte im Zusammenhang mit dem Sozialistengesetz nicht mehr die Rede. Stattdessen betonte Wehler 1995 die Ambivalenz der Bismarckschen Sozialistenpolitik: "Auf der einen Seite gab es eine genuine Furcht und Sorge vor ihren radikalen Fernzielen, auf der anderen Seite wurde diese Angst machiavellistisch ausgenutzt. ${ }^{36}$ - Auf diese Interpretation werden sich vermutliche viele Historiker verständigen können.

\section{»Revolution« im Reichstag}

Ein Blick auf die längerfristige Entwicklung der politischen Semantik eröffnet die Möglichkeit, die Bedeutung von Revolutionsängsten für die politische Kultur des

\footnotetext{
30 Pöls, Sozialistenfrage.

31 Pöls, Sozialistenfrage, S. 81.

32 Fricke/ Knaack, Dokumente, Bd. 1, S. IX.

33 Groh, Dieter: Negative Integration und revolutionärer Attentismus. Die deutsche Sozialdemokratie am Vorabend des Ersten Weltkrieges, Berlin 1973.

34 Wehler, Hans-Ulrich: Das deutsche Kaiserreich. 1871-1918, 4. Aufl., Göttingen 1980, S. 96.

35 Pflanze, Otto: Bismarcks Herrschaftstechnik als Problem der gegenwärtigen Historiographie, München 1982, S. 13.

36 Wehler, Gesellschaftsgeschichte, Bd. 3, S. 907.
} 
Kaiserreichs jenseits der situationsgebundenen Urteile und machttaktischen Kalküle einzelner politischer Akteure auszuloten. Je häufiger von der "Revolution" gesprochen wurde und je prominenter dieses Motiv in der politischen Debatte war, desto ausgeprägter waren politische Befürchtungen oder Hoffnungen in seinem Begriffsumfeld angesiedelt. Jede Rede von »der Revolution«, »revolutionären Bestrebungen«, "revolutionären Ansichten« oder »der Revolutionspartei» evozierte das Bild einer radikalen Herausforderung der politischen und gesellschaftlichen Ordnung, ganz gleich ob affirmativ oder kritisch verstanden. Im Folgenden soll daher die Prominenz des Revolutionsbegriffs in zwei für die Politik im Kaiserreich besonders relevanten Kommunikationskontexten überprüft werden: Zum einen werden die Debatten im Reichstag daraufhin untersucht, wie oft die Redner den Begriff "Revolution" verwendeten. Das Parlament war eine der wichtigsten Arenen der politischen Auseinandersetzung im Kaiserreich. Aufgrund des allgemeinen Männerwahlrechts waren hier von Anfang an alle relevanten politischen Strömungen und Meinungen vertreten. Man kann die Reichstagsdebatten daher mit einiger Plausibilität als Schlüsselquellen der öffentlichen politischen Kommunikation ansehen. Dies gilt in besonderem Maße für die Jahre zwischen 1878 und 1890, in denen die sozialdemokratische Presse und Versammlungsöffentlichkeit unterdrückt waren und sozialistische Positionen allein im Reichstag gefahrlos vertreten werden konnten. Zum anderen werden die geheimen »Übersichten über die allgemeine Lage der sozialdemokratischen und revolutionären Bewegung“ analysiert, die - mit Unterbrechungen - zwischen 1878 und 1913 von der Berliner Politischen Polizei zusammengestellt wurden. Im Unterschied zu den Reichstagsdebatten waren die "Übersichten" als behördeninterne Texte nicht auf öffentliche Wirkung angelegt. Es ist daher zu vermuten, dass ihre Begriffspraxis den hegemonialen Wahrnehmungsmustern und Sagbarkeitsregeln der Überwachungsbehörden entsprach. In beiden Fällen handelt es sich um serielle Quellen, wobei die Reichstagsprotokolle das gesamte Kaiserreich, die polizeilichen Überwachungsberichte immerhin den Zeitraum von 1878 bis 1913 abdecken. Selbstverständlich kann eine Auszählung von Worthäufigkeiten keine tiefergehende qualitative Analyse ersetzen. Auch ignoriert ein solches Verfahren den Kontext der Wortverwendung: Weder beachtet es, auf welche Personen, Äußerungen oder Handlungen sich die Etikettierung als "revolutionär" im Einzelfall bezog, noch lässt sich berücksichtigen, ob damit eine positive oder negative Einstellung zur "Revolution" gemeint war, noch ist überhaupt zu ermitteln, was konkret die Redner oder Autoren unter "Revolution» oder einer "revolutionären Strategie» verstanden, noch wird klar, ob es sich um eine Selbst- oder Fremdzuschreibung handelte. All dies ist in Rechnung zu stellen. Aber gerade, weil eine Analyse der Worthäufigkeit alle Kontextbezüge abblenden muss, eröffnet sie die Chance, im 
Längsschnitt zu verfolgen, welches Gewicht dem Begriff in der öffentlichen Debatte bzw. in der politisch-polizeilichen Weltwahrnehmung zukam. Je häufiger von »Revolution«, "Revolutionären« oder "revolutionären« Aktionen die Rede war, desto stärker wurde die Arbeiterbewegung mit diesem Begriffsfeld assoziiert oder bildete dieses zumindest den semantischen Referenzhorizont ihrer Bewertung.

Wie häufig kamen die Reichstagsabgeordneten im Kaiserreich auf die »Revolution« zu sprechen? Graphik 1 zeigt das Ergebnis einer Auszählung auf Basis der digitalisierten Wortprotokolle der Verhandlungen des deutschen Reichstags zwischen 1871 und 1918. ${ }^{37}$ Gezählt wurden alle Seiten der gedruckten Protokolle, auf denen das Wort "Revolution" sowie entsprechende Adjektive und Komposita vorkommen. Da diese auf einer Druckseite mehrfach auftauchen können, liegt die tatsächliche Häufigkeit der Begriffe über den erhobenen Zahlen. Trotzdem geben die erhobenen Daten einen guten Näherungswert. Um längerfristige Trends zu ermitteln, wurden jährliche Durchschnitte bezogen auf die jeweilige Legislaturperiode errechnet. Hierdurch werden kurzfristige Schwankungen zwischen einzelnen Jahren geglättet.

37 Die der Graphik zugrunde liegenden Daten beruhen auf einer Volltextsuche in der digitalisierten Version der Reichstagsprotokolle mit den Erscheinungsjahren 1871 bis 1918 nach den Suchworten »revolution" und »reform». Diese erfassen außer den Substantiven auch adjektivische Verwendungen und alle Komposita. Ausgewiesen wird die Anzahl der Seiten, die entsprechende Zeichenfolgen enthalten. Auf einer Seite können mehrere Nennungen vorkommen, sodass der ermittelte Wert nicht mit der Häufigkeit der tatsächlichen Wortverwendung identisch ist. Eine weitere Ungenauigkeit resultiert daraus, dass die zeitliche Zuordnung der Funde über die Suchfunktion der digitalen Ausgabe der RT-Protokolle nach dem Erscheinungsjahr der Protokolle erfolgt, das z.T. nach dem Jahr lag, in dem die jeweiligen Reden gehalten wurden. Um diesen Effekt zu mildern und jährliche Schwankungen zu glätten, wurden Jahresdurchschnitte bezogen auf die jeweiligen Legislaturperioden gebildet. Quelle: Verhandlungen des Deutschen Reichstags 1871-1918, https://www.reichstag-abgeordnetendatenbank.de/volltext.html (7.1.2020). 


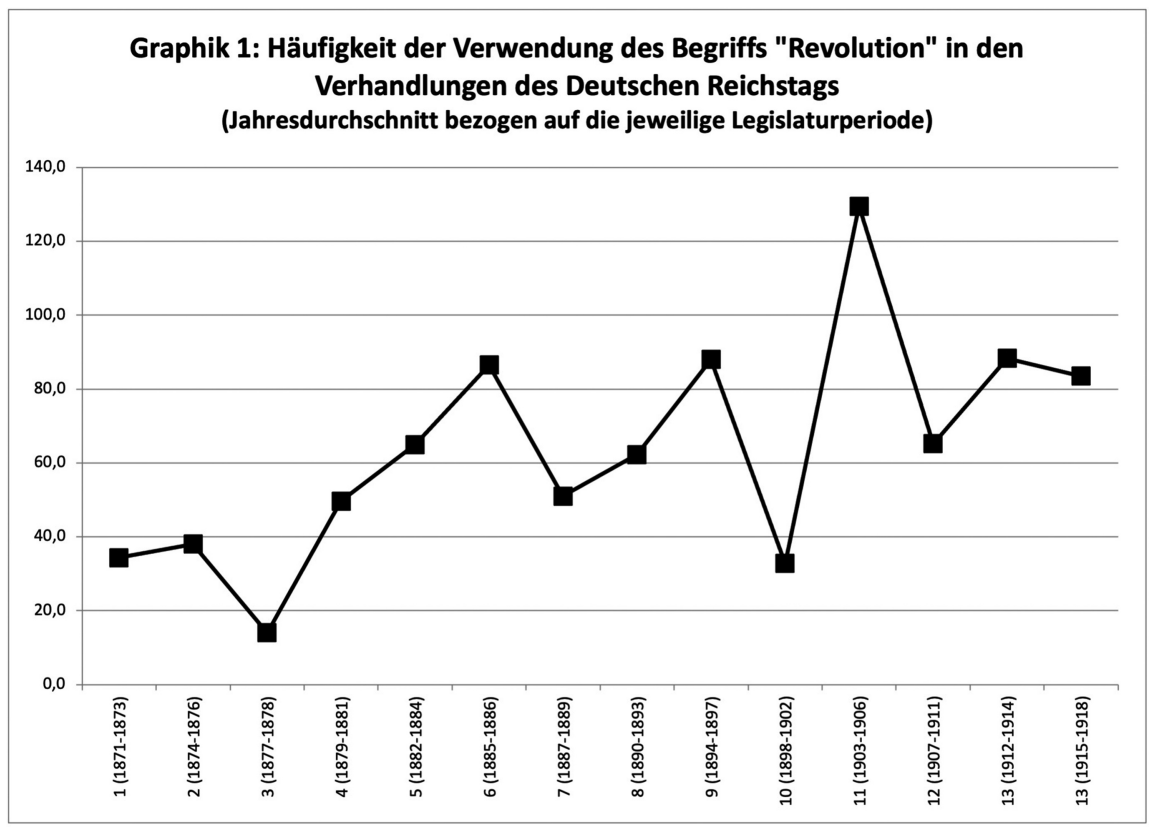

Während der ersten drei Legislaturperioden nach der Reichsgründung haben die Abgeordneten nur selten über vergangene oder zukünftige "Revolutionen" geredet - trotz der zeitlichen Nähe zu den spektakulären Ereignissen der Pariser Kommune. In den folgenden Jahrzehnten lassen sich drei Begriffskonjunkturen erkennen: Die erste setzt Ende der 1870er Jahre ein und erreichte Mitte der 1880er ihren Höhepunkt. In diesen Jahren wurden die beiden Kaiserattentate von 1878 erörtert, das Sozialistengesetz verabschiedet und über die anhaltende Untergrundtätigkeit der Sozialdemokraten debattiert. Auch viel beachtete anarchistische Anschläge wie die Platzierung einer Bombe bei der Einweihung des Niederwalddenkmals am 28. September 1883 und die Ermordung des Frankfurter Polizeipräsidenten Rumpff am 13. Januar 1885 fielen in diese Zeit und haben Revolutionsängste geschürt. ${ }^{38}$ In der zweiten Hälfte der 1880er Jahre und in den frühen 1890er Jahren nahm die Prominenz des Revolutionsbegriffs merklich ab, um Mitte der 1890er einen zweiten Höhepunkt zu erreichen, der vor allem mit dem Wachstum der sozialdemokratischen Partei nach Auslaufen des Sozialistengesetzes und dem gescheiterten Versuch der Reichsregierung zusammenhing, die SPD

38 Haupt, Heinz-Gerhard: Den Staat herausfordern. Attentate in Europa im späten 19. Jahrhundert, Frankfurt 2019, S. 26; Mühlnikel, Attentate, S. 68 - 87. Vgl. auch Härter, Karl u. a. (Hrsg.): Vom Majestätsverbrechen zum Terrorismus. Politische Kriminalität, Recht, Justiz und Polizei zwischen Früher Neuzeit und 20. Jahrhundert, Frankfurt/M. 2012. 
mit der sog. "Umsturzvorlage« erneut einem Sondergesetz zu unterwerfen. ${ }^{39} \mathrm{Al}-$ lein für die Jahre 1894 und 1895, in denen über diese Vorlage debattiert wurde, findet sich auf 362 Seiten der Reichstagsprotokolle der Begriff »Umsturz» und auf 201 Seiten der Begriff "Revolution«.40 Seinen absoluten Höhepunkt erreichte die Reichstagskarriere des Revolutionsbegriffs allerdings während der elften Legislaturperiode zwischen 1903 und 1906: Auf 518 Protokollseiten taucht er während dieser vier Jahre auf - durchschnittlich 129 Mal pro Jahr. Allerdings hatte sich jetzt der Bezugsraum des Begriffs verschoben: Im Zentrum des Interesses und der Befürchtungen standen nicht mehr innerdeutsche Konflikte, sondern die revolutionäre Bewegung in China, vor allem aber die erste Russische Revolution von 1905.

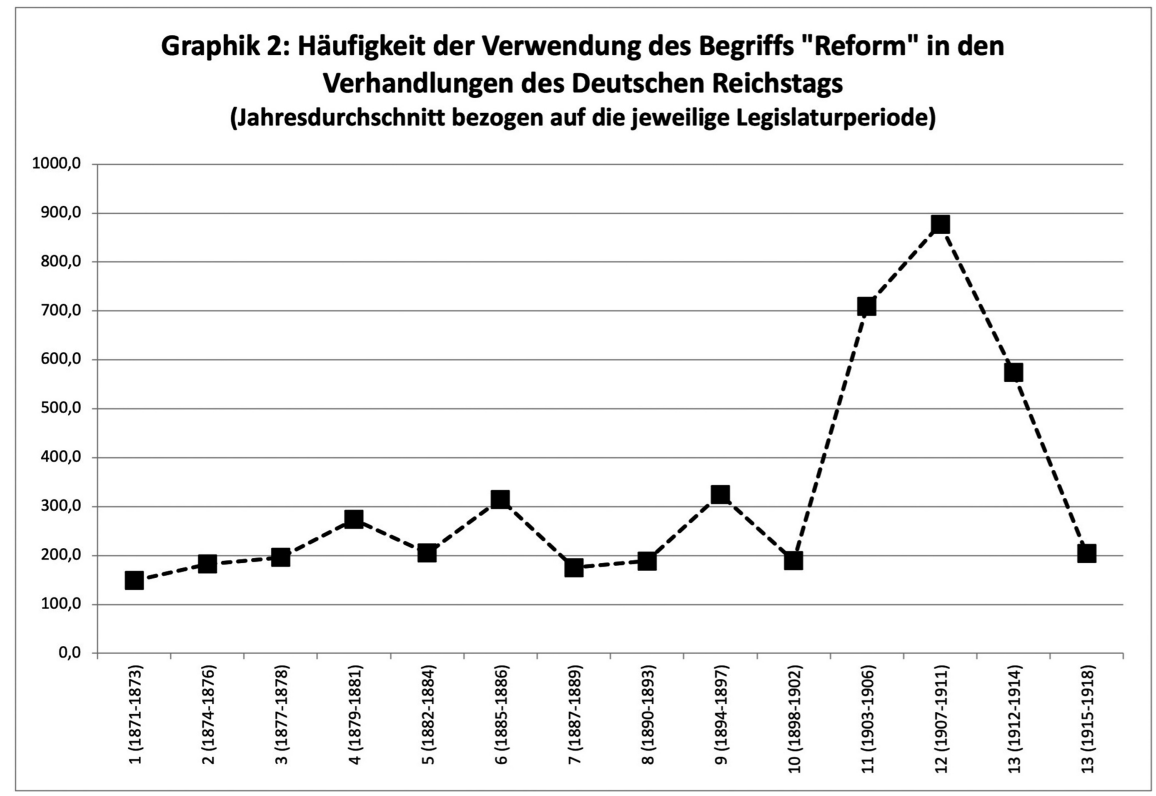

Aus einem innenpolitischen Kampf- und Propagandabegriff war mehr und mehr ein auf äußere Ereignisse bezogener Beschreibungsbegriff geworden. Obwohl im Reichstag mehr als jemals zuvor von »der Revolution« geredet wurde, verlor der Begriff einiges an polarisierender Brisanz. Dafür machte das Schlagwort von der "Reform» eine kometenhafte Karriere: Nachdem die Häufigkeit sei-

39 Vgl. Kupfer, Torsten: Geheime Zirkel und Parteivereine. Die Organisation der deutschen Sozialdemokratie zwischen Sozialistengesetz und Jahrhundertwende, Essen 2003.

40 Zur antisozialistischen Propaganda und Repressionspolitik nach Auslaufen des Sozialistengesetzes vgl. Saul, Klaus: Der Staat und die »Mächte des Umsturzes». Ein Beitrag zu den Methoden antisozialistischer Repression und Agitation vom Scheitern des Sozialistengesetzes bis zur Jahrhundertwende (AfS 12), Bonn 1972, S. $293-350$. 
ner Verwendung über drei Jahrzehnte ohne klaren Trend stagniert hatte, schoss sie zwischen 1903 und 1914 ruckartig in die Höhe (vgl. Graphik 2). Zugespitzt könnte man sagen, dass die notorische "Revolutionsfurcht" in den Jahren vor Ausbruch des Ersten Weltkrieges externalisiert wurde, während die innenpolitischen Debatten mehr und mehr unter dem Signum evolutionären Wandels standen.

»Revolution« und Politische Polizei

Obwohl sich die Autoren im Berliner Polizeipräsidium bei der Zusammenstellung der »Übersichten über die allgemeine Lage der sozialdemokratischen und revolutionären Bewegung» bzw. ab 1898 der »Übersichten über die allgemeine Lage der sozialdemokratischen und anarchistischen Bewegung " um eine nüchterne Diktion bemühten, sind die Texte mit politischen Einschätzungen und Wertungen durchsetzt, aus denen sich die polizeiliche Perzeption der Linken und die obrigkeitliche Interpretation ihrer Strategien und Ziele erkennen lässt. Initiiert wurde die Berichtserie zwar, um die Wirksamkeit des "Gesetzes gegen die gemeingefährlichen Bestrebungen der Sozialdemokratie» zu überprüfen. Neben den Sozialdemokraten standen aber von Anfang an auch anarchistische Gruppen im Visier der polizeilichen Beobachtung, die in den 1880er und frühen 1890er Jahren im Reich und in anderen europäischen Ländern mit Aufsehen erregenden Attentaten von sich reden machten. ${ }^{41}$ Während sich die deutschen Sozialdemokraten seit den späten 1870er Jahren um eine strikte Abgrenzung von der anarchistischen »Propaganda der Tat« bemühten und prominente Radikale wie Johann Most und Wilhelm Hasselmann, die gewaltsame Aktionen gegen Staat und Bourgeoisie befürworteten, aus der Partei ausschlossen, neigten die »Übersichten" vor allem während der 1880er Jahre dazu, Sozialdemokraten und Anarchisten als verfeindete Brüder im Geiste zu betrachten. Auch wenn nicht zu verkennen sei, hieß es in der Übersicht vom 31. Dezember 1880, dass sich Most von den Grundsätzen der Sozialdemokraten weit entfernt habe, ändere dies nichts daran, dass beide Seiten eine revolutionäre Zukunftserwartung teilten:

"Die Sozialisten Bebel-Liebknechtscher Richtung sind allerdings ebenso wie Most der Überzeugung, daß auf friedlichem Wege für sie nichts zu erreichen ist und daß daher die gewaltsame Revolution mit der Zeit kommen muß. Sie wissen aber sehr wohl, daß dieser Zeitpunkt noch fern liegt, daß sie dazu noch einer langen und sorgfältigen Vorbereitung bedürfen. Deshalb suchen sie sich mit den gegenwärtigen Verhältnissen so gut wie mög-

41 Vgl. Mühlnikel, Attentate. 
lich abzufinden und sträuben sich, durch unüberlegte Schritte den später sicher zu erwartenden Erfolg aufs Spiel zu setzen. «42

Ähnliche Formulierungen finden sich in den Berichten der folgenden Jahre immer wieder. Erst um die Jahrhundertwende, als der Höhepunkt des anarchistischen Terrorismus in Europa längst überschritten war, trennten die »Übersichten" deutlicher zwischen der sozialdemokratischen Massenbewegung und den verbliebenen anarchistischen Grüppchen und Einzelpersonen. Hier lässt sich mit der Zeit eine gewisse Tendenz zu einer differenzierteren Einschätzung und Kategorisierung des »linken« Lagers erkennen. Der ostdeutsche Herausgeber der Übersichten, Dieter Fricke, hat die große Aufmerksamkeit der Polizeibehörden für den Anarchismus als ideologisch motivierte Fehldeutung kritisiert:

»Entsprechend einer altbewährten Methode der Reaktion bei der Verfolgung und Unterdrückung der sozialistischen Arbeiterbewegung wurde eine revolutionäre Haltung grundsätzlich als anarchistisch diffamiert. Die immer wieder in den ,Übersichten anzutreffende Methode, revolutionäre Sozialdemokraten mit den Anarchisten schlechthin gleichzusetzen, diente zur Rechtfertigung bzw. Stimulierung eines noch brutaleren Vorgehens gegen jene. «43

Mit diesem Urteil befand sich Fricke 1983 im Einklang mit der geschichtspolitischen Leiterzählung der SED, die die marxistische Sozialdemokratie zur einzig wahren Repräsentantin des historischen Fortschritts und der Klasseninteressen der Arbeiterschaft stilisierte. Trotzdem lag er nicht falsch, wenn er die überproportionale Aufmerksamkeit der Polizeibehörden für die gewaltgeneigten Anarchisten monierte: Im Vergleich zur Sozialdemokratie, deren Wähleranteil seit Mitte der 1880er Jahre kontinuierlich stieg und bis zu den Reichstagswahlen von 1912 auf fast 35\% wuchs, waren die versprengten Anarchisten ein unbedeutendes Häuflein.

Tatsächlich sind die „Übersichten» in dieser Hinsicht widersprüchlich: Einerseits vermerken sie immer wieder, dass sich die Sozialdemokraten im Rahmen der Legalität bewegten und sich von den Anarchisten distanzierten, um den Behörden keine Angriffsfläche zu bieten. "Das Verhältnis der Sozialdemokraten zu den Anarchisten bzw. Mostianern ist äußerlich ein schroffes. In England und der Schweiz sind wiederholt Prügeleien zwischen ihnen vorgekommen«, hieß es 1884. Andererseits konstatiert man, dass »die Grundanschauungen der Sozialdemokraten und der Sozialrevolutionäre ganz dieselben sind und beide Parteien lediglich in der Wahl der Mittel [...] voneinander abweichen. «" Zugleich zeigen die 
Detailinformationen über sozialdemokratische und anarchistische Aktivitäten im In- und Ausland, dass die Analytiker der Polizei die grundsätzlichen Unterschiede zwischen beiden Richtungen sehr wohl sahen. Während etwa von einer Anarchistenversammlung in Paris berichtet wurde, diese habe "die Ausrottung der Monarchen, Kapitalisten und Pfaffen durch die Propaganda der Tat dringend" empfohlen, hieß es von den deutschen Exil-Sozialdemokraten in der Schweiz, dass "sie in demonstrativer Weise die Taten der Anarchisten zu verabscheuen erklären. ${ }^{45} \mathrm{Im}$ Laufe der Zeit tendierten die Analysen der politischen Polizei dazu, deutlicher zwischen der legalistisch agierenden Sozialdemokratie und den anarchistischen Gruppen und ihrer terroristischen Strategie zu unterscheiden. Der Wechsel in der Titulierung Ende der 1890er Jahre macht dies deutlich. Je stärker sich die Erwartung gewaltsamen revolutionären Handelns auf die anarchistischen Gruppen konzentrierte, desto weniger wurden die Aktivitäten der Sozialdemokratie noch mit dem Schreckbild der »Revolution« assoziiert.

Als ein Indikator für den Stellenwert, den Revolutionsängste für die politischpolizeiliche Situationsdeutung im Kaiserreich hatten, kann auch hier die Häufigkeit gelten, mit der die obrigkeitlichen Beobachter in ihren Berichten über die "Revolution" schrieben. ${ }^{46}$ Außer dem Begriff »Revolution" und seinen Komposita wurde wiederum der Gegenbegriff »Reform» ausgezählt, um zu überprüfen, ob und bis zu welchem Grad die Arbeiterbewegung bis zum Beginn des Ersten Weltkrieges aus Sicht der polizeilichen Beobachter mit einem systemkonformen, evolutionären Politikkonzept assoziiert wurde.

\footnotetext{
45 Ebd., S. 251, 259.

46 Die folgenden Graphiken beruhen auf einer Auszählung des Texts aller 34 »Übersichten« in der von Dieter Fricke und Rudolf Knaack besorgten Edition. Fricke/ Knaack, Dokumente, Bd. 1-3. Erfasst wurde jede Nennung der Zeichenfolge "revolution" und "reform» unter Ausschluss des editorischen Apparates in den Fußnoten. Damit wurden sowohl Substantive als auch Adjektive sowie alle Komposita erfasst, die die entsprechenden Zeichenfolgen enthalten. Da nur die Worthäufigkeit registriert wurde, bleiben inhaltliche Aspekte unbeachtet. Die Worte »Revolution«, "Reform«, "revolution» oder "reformistisch" etc. können sich also auf die Politik sozialdemokratischer oder anarchistischer Gruppen beziehen, aber z. B. auch auf die Eigenbezeichnung von Publikationen oder politischer Organisationen in Deutschland und im Ausland. Auch wird nicht zwischen positiven (»Die Gruppe XY strebt eine Revolution an«) und negierenden Verwendungen (»AB spricht sich gegen eine revolutionäre Strategie aus«) unterschieden. Die Auszählung gibt also nur über die Häufigkeit Auskunft, mit der die Lageanalysen der Politischen Polizei auf die genannten Begriffe referieren. Da die Berichtszeiträume der Übersichten unterschiedlich lang sind, lassen sich die Befunde nicht exakt auf einzelne Jahre beziehen. Aus diesem Grund sind auf der x-Achse die einzelnen Berichte und keine Jahreszahlen aufgetragen. Für die Jahre 1888, 1890 - 1892, 1894-1896 liegen keine Berichte vor. Für Unterstützung bei der Auszählung und Datenerfassung danke ich Laura Bönemann.
} 


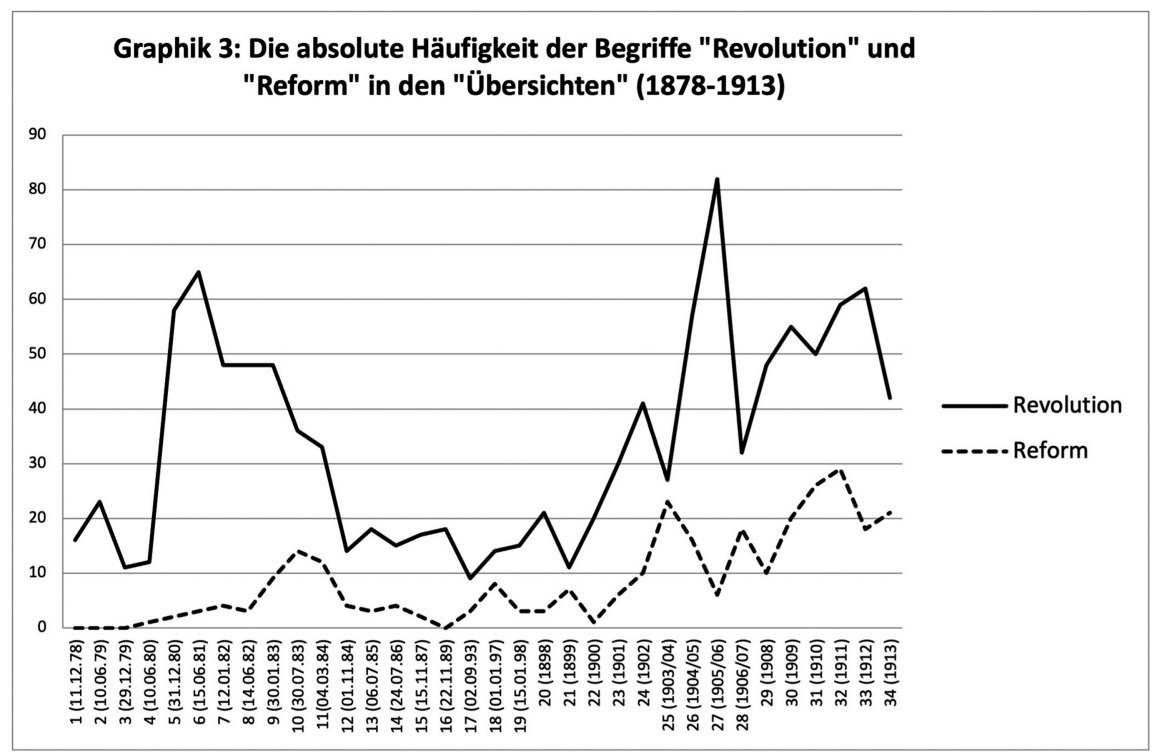

Graphik 3 lässt erkennen, dass der Revolutionsbegriff in den beiden hauptsächlichen Beobachtungsperioden während der 1880er Jahre und in der Zeit nach der Jahrhundertwende eine herausragende Rolle spielte. Für die Geltungsdauer des Sozialistengesetzes fällt eine bemerkenswerte Zweiteilung auf: $\mathrm{Zu}$ Beginn der 1880er Jahre zeigt sich zunächst ein rapider Anstieg: Die sechste Übersicht vom 15. Juni 1881 verwendete 65 Mal den Begriff »Revolution». Anschließend fiel die Verwendungshäufigkeit immer weiter und lag 1889 bei 17 Mal. Als die Berichterstattung nach mehrjähriger Unterbrechung kurz vor der Jahrhundertwende wieder in einen regelmäßigen Rhythmus kam, nahm die Prominenz des Revolutionsbegriffs bis zu einem Maximum von 82 Nennungen in der siebenundzwanzigsten Übersicht für die Jahre 1905/06 zu, fiel anschließend rasch ab, um bis 1912 erneut schrittweise zu steigen. Hier spielte die Massenstreikdebatte in der deutschen Sozialdemokratie eine Rolle, in den Jahren 1905/06 stand aber wie schon in den Reichstagsdebatten vor allem die Russische Revolution im Zentrum der Aufmerksamkeit. Der Begriff "Reform» war in den Einschätzungen der politischen Polizei weit weniger prominent, wies aber ebenfalls zwei Häufigkeitshöhepunkte auf: In der ersten Hälfte der 1880er Jahre bot hierzu vor allem die Bismarcksche Versicherungsgesetzgebung Anlass, nach der Jahrhundertwende bezogen sich die entsprechenden Nennungen auch auf die programmatischen und strategischen Debatten in den sozialistischen Parteien in Deutschland und in anderen europäischen Ländern. Im annähernd parallel ansteigenden Kurvenverlauf von »Revolution" und »Reform» spiegelt sich grosso modo die polizeiliche Beobachtung der in- 
nerparteilichen Flügelkämpfe zwischen den reformorientierten Kräften und der radikalen Linken während des Vorkriegsjahrzehnts.

Um den Stellenwert der Revolutionssemantik für die polizeiliche Sicht auf die Arbeiterbewegung angemessen zu bestimmen, ist ein Präzisierungsschritt erforderlich, durch den die bisherigen Befunde in einem etwas anderen Licht erscheinen. Zwischen 1878 und 1913 ist der Umfang der polizeilichen »Übersichten" erheblich gewachsen. Reichten anfangs 13-14 Seiten aus, um die »allgemeine Lage der sozialdemokratischen und revolutionären Bewegung« zu beschreiben, breiteten die polizeilichen Beobachter ihre Erkenntnisse in den Jahren vor Kriegsbeginn auf über 100 Seiten aus. ${ }^{47}$

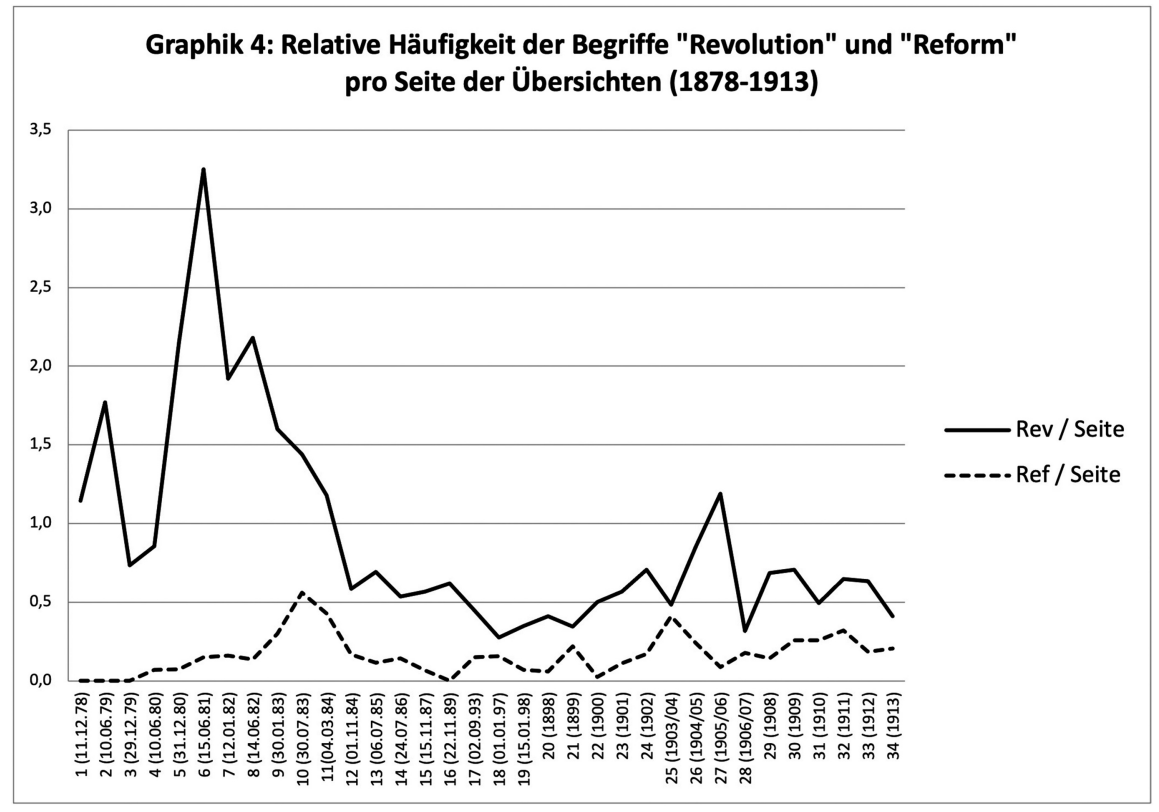

Dies hatte Rückwirkungen auf die relative Prominenz der analysierten Begriffe, denn wenn in einem 20-seitigen Bericht 50 oder 60 Mal von "Revolution" gesprochen wurde, zeigt dies eine größere Relevanz des Begriffes an, als wenn dies in einem Bericht von 100 Seiten geschah. Unter Berücksichtigung der Seiteninflation ergeben die oben vorgestellten Befunde ein anderes Bild (vgl. Graphik 4). Die relative Häufigkeit des Revolutionsbegriffs erreichte schon in den ersten Jahren nach Erlass des Sozialistengesetzes ihren Höhepunkt: Zu Anfang der 1880er Jahre ist die Arbeiterbewegung von ihren polizeilichen Beobachtern am häufigsten mit dem Revolutionsbegriff assoziiert worden. Ab Mitte des Jahrzehnts war es mit die-

47 Die Seitenzählung bezieht sich auf die Druckversion der Übersichten in der Edition von Fricke. 
ser obsessiven Revolutionsfurcht aber schon wieder vorbei. Von jetzt an bis zum Kriegsbeginn pendelte die relative Häufigkeit der Begriffsverwendung um einen Wert von 0,5 Nennungen pro Seite. Lediglich der Schock der Russischen Revolution von 1905 sorgte für eine kurzzeitige Begriffskonjunktur. Sieht man von diesem externen Ereignis ab, stagnierte die relative Prominenz des Revolutionsbegriffs seit Mitte der 1880er Jahre ohne klaren Auf- oder Abwärtstrend auf relativ niedrigem Niveau. Hinsichtlich des Begriffs "Reform» erscheinen auch jetzt die frühen 1880er Jahre als die Phase größter relativer Prominenz.

Die Veränderung der polizeilichen Außenwahrnehmung korrespondierte mit dem Wandel der Revolutionserwartung in der sozialistischen Arbeiterbewegung. Nachdem die nationale Frage 1871 nicht revolutionär und großdeutsch von unten, sondern autoritär, kleindeutsch-preußisch und von oben gelöst worden war, begann nicht nur die revolutionäre Naherwartung zu verblassen. Auch die Vorstellung, die führende Sozialdemokraten von »der Revolution« hatten, veränderte sich. Dieter Groh hat dies in seiner klassischen Studie mit dem Begriff des »revolutionären Attentismus« auf den Punkt gebracht.48 In einer deterministisch verflachten Marx-Rezeption gingen führende Köpfe der Sozialdemokratie wie Bebel oder Liebknecht mehr und mehr von der Annahme aus, die innere Entwicklung der kapitalistischen Gesellschaft würde von sich aus auf eine Situation der Destabilisierung und letztlich des Zusammenbruchs hintreiben. Diesen Prozess könne und solle man nicht beschleunigen, sondern müsse ihn letztlich nur abwarten. Zwischenzeitlich habe man sich auf die Organisation und Schulung des Proletariats zu konzentrieren, dem nach dem Kollaps der alten Ordnung die politische Macht zufallen werde. ${ }^{49}$

Diese abwartende Revolutionshoffnung wurde nicht zuletzt durch die Große Depression ab 1873 stimuliert, die als letzte große Krise des Kapitalismus interpretiert wurde. Auch Engels deutete die Depression 1886 als letzte Phase der kapitalistischen Wirtschaft vor dem Ausbruch der "unvermeidlichen sozialen Revolution ${ }^{50}$. Bebel teilte diese Vermutung und prognostizierte in den 1880er Jahren immer wieder den baldigen "großen Kladderadatsch«: »Ich lege mich jeden Tag mit dem Gedanken schlafen, daß das letzte Stündlein der bürgerlichen Gesellschaft in Bälde schlägt. «51 Diese Formulierung bringt den "revolutionären Attentismus« von Bebel und Genossen besonders treffend zum Ausdruck: Die Revoluti-

48 Groh, Negative Integration und revolutionärer Attentismus.

49 Liebknecht, Wilhelm: Zu Trutz und Schutz. Festrede gehalten zum Stiftungsfest d. Crimmitschauer Volksvereins am 22. Oktober 1871 (nach e. stenogr. Niederschrift), Leipzig 1874, S. 17f. Zitiert nach Welskopp, Banner, 704.

50 Groh, Dieter/ Brandt, Peter: „Vaterlandslose Gesellen«. Sozialdemokratie und Nation 1860 - 1990, München 1992, S. 35.

51 Brief an Engels von 1885, zitiert nach Groh/ Brandt, Sozialdemokratie und Nation, S. 36. 
on war ein Ereignis, das von den Sozialdemokraten quasi "im Schlaf« erwartet werden konnte.

Wenn nicht die finale Krise des Kapitalismus dem bürgerlichen System den Garaus machte, so eine weitere, unter führenden Sozialdemokraten populäre Vermutung, dann wäre es sicherlich ein kommender großer Krieg. August Bebel ging ab den frühen 1880er Jahren davon aus, dass ein europäischer Krieg sehr wahrscheinlich die ersehnte Revolution, den "großen Kladderadatsch« auslösen würde. Und von Friedrich Engels stammt die berühmte Prognose vom Dezember 1887, dass nach einem künftigen europäischen Krieg »die Kronen zu Dutzenden über das Straßenpflaster rollen [werden] und niemand sich findet, der sie aufhebt. ${ }^{52}$ Diese Vorhersage ist nicht nur deshalb bemerkenswert, weil sie sich 1918 auf geradezu unheimliche Weise bewahrheitete, sondern auch, weil sich Engels' Revolutionserwartung mit der Revolutionsfurcht Bismarcks deckte, der im gleichen Jahr im Zusammenhang mit den Verhandlungen über den geheimen Rückversicherungsvertrag zwischen Russland und Deutschland seine Sorgen vor einem möglichen europäischen Krieg artikulierte, der unweigerlich revolutionäre Umbrüche nach sich ziehen werde: „Der Krieg, sei der nun siegreich oder nicht, wird die Revolution in mehr als einem Lande entfesseln. «53 Auch diese Revolutionsprognose wies der Arbeiterbewegung eine passive Rolle zu: Den zukünftigen Krieg konnte man nur abwarten.

Die Abkehr von einem proaktiv gedachten Revolutionsszenario lässt sich schließlich auch daran erkennen, wie sich die deutschen Sozialdemokraten im späten Kaiserreich zur Frage des politischen Streiks positionierten. Aus Sicht der Polizeibehörden waren große Arbeitskämpfe nicht allein wirtschaftliche Auseinandersetzungen zwischen den Arbeitsmarktparteien, sondern eine potentielle Gefahr für die politische Ordnung: Der überraschend ausgebrochene große Streik der Bergarbeiter im Jahr 1889 führte die überforderten preußischen Polizeibehörden zu der irrigen Annahme, die treibenden Elemente seien die "staatsgefährlichen, auf den Umsturz der bestehenden Gesellschaftsordnung gerichteten Bestrebungen" gewesen. ${ }^{54}$ Obwohl die Sozialdemokraten unter den Bergleuten des Ruhrgebiets einen schweren Stand hatten und mit der Organisation dieses und anderer Bergarbeiterstreiks nichts zu tun hatten, nahm man den 1889er Streik zum Anlass für eine umfassende Verstärkung der regionalen Polizeikräfte.

52 Zitiert nach Engelberg, Ernst: Bismarck, Bd. 2: Das Reich in der Mitte Europas, Berlin 1998, S. 505. Allerdings befürchtete Engels zugleich, dass im Falle eines neuen Krieges entweder die Arbeiterschaft "ins patriotische Geheul mit einstimmen (würden)«, oder dass Arbeiterbewegung und Sozialdemokratie dann noch weitaus brutaler unterdrückt und verfolgt würden als unter dem Sozialistengesetz. Groh/ Brandt, Sozialdemokratie und Nation, S. 33.

53 Bismarck im November 1887, zitiert nach Engelberg, Bismarck, Bd. 2, S. 505.

54 Jessen, Polizei im Industrierevier, S. 150. 
In der sozialdemokratischen "Massenstreik«-Debatte nach der Jahrhundertwende zeigte sich allerdings, dass die obrigkeitlichen Sorgen, sozialdemokratische Agitatoren könnten eine Streikbewegung zur revolutionären Mobilisierung nutzen, unbegründet waren. Inspiriert durch Streiks zur Erlangung des Wahlrechts in Schweden und Belgien, einen weiteren großen Bergarbeiterstreik im Ruhrgebiet im Januar 1905 und die russische Revolution im gleichen Jahre debattierten SPD und Gewerkschaften in den Jahren 1905/06 darüber, ob man "Massenstreiks" als Instrument zur Durchsetzung politischer Ziele befürworten sollte. Während sich die Freien Gewerkschaften klar dagegen aussprachen, schlug die SPD zunächst einen anderen Kurs ein. Ein Parteitag in Jena beschloss im September 1905, dass man den Massenstreik zwar nicht als offensives Kampfmittel, wohl aber als Abwehrinstrument gegen eine mögliche Einschränkung des Wahlrechts oder des Koalitionsrechts akzeptierte.55 Ein Jahr später wurde diese sehr beschränkte Öffnung zum politischen Streik allerdings schon wieder kassiert. Im "Mannheimer Abkommen" vom September 1906 räumte die SPD den Gewerkschaften faktisch ein Vetorecht gegen politische Streiks ein, die damit praktisch ausgeschlossen waren.

Ohnehin hatte man politische Streiks nur zur Verteidigung des Wahl- und Koalitionsrechts für legitim gehalten, also zur Sicherung systemimmanenter Partizipationsrechte, die die Ordnung des Kaiserreichs - wenn auch mit etlichen Mängeln und Begrenzungen - gewährte. Nicht zuletzt das Sozialistengesetz hatte in Kombination mit dem modernen Reichstagswahlrecht die Fokussierung der sozialistischen Arbeiterbewegung auf die Wahlkämpfe und die Parlamentswahlen erheblich verstärkt. An der Wahlurne konnte man seine Popularität und die breite Resonanz der Sozialdemokratie in der Bevölkerung beweisen - die von Wahl zu Wahl steigenden Stimmanteile zeigten es. Als die SPD in den Reichstagswahlen 1890 erstmals mehr Stimmen als jede andere Partei erhalten hatte, entfachte dies beim alten Friedrich Engels in London noch einmal Revolutionshoffnungen: "Der 20. Februar [der Wahltag] ist der Tag, an dem die deutsche Revolution eröffnet wird " meinte er, und weiter: »In drei Jahren können wir die Landarbeiter haben und dann haben wir die Kernregimenter der preußischen Armee. Dann ist die ganze alte Wirtschaft Kladderadatsch und wir herrschen. ${ }^{56}$ So ist es nicht gekommen, aber selbst in diesem Szenario sollte der Wahlerfolg den Durchbruch bringen, nicht die revolutionäre Erhebung. „Die Sozialdemokratie ist eine revolutio-

55 Geschichte der Gewerkschaften (Hans-Böckler-Stiftung): Verhältnis von SPD und Freien Gewerkschaften. Debatte über Massenstreik, https://www.gewerkschaftsgeschichte.de/Debatte-ueber-massen streik.html (01.04.2021), dort auch die Dokumentation der entsprechenden Beschlüsse.

56 Briefäußerungen von Engels, zitiert nach Groh/ Brandt, Sozialdemokratie und Nation, S. $51 \mathrm{f}$. 
näre, aber keine Revolution machende Partei« hat Karl Kautsky die Sache auf den Punkt gebracht.

Wenn einerseits festzustellen ist, dass sich die politisch-polizeiliche Beschreibung der revolutionären Bedrohung in den 1890er Jahren von der pauschalen Stigmatisierung aller "linken« Kräfte entfernte und sich andererseits die sozialistische Arbeiterbewegung mehrheitlich von einem proaktiven Revolutionsverständnis löste, heißt dies nicht, dass in der antisozialistischen Agitation und Publizistik nicht weiter das Feindbild des aufrührerischen Sozialdemokraten gepflegt und die Furcht vor der Revolution geschürt wurden. Dem fleißigen, integrierten, politisch unauffälligen Arbeiter wurde der gefährliche, aufrührerische, sozialdemokratisch verhetzte Arbeiter gegenübergestellt, der oft zusätzlich moralisch disqualifiziert wurde. ${ }^{57}$ Besonders tat sich hierbei der 1903 als Reaktion auf die sozialdemokratischen Wahlerfolge gegründete "Reichsverband gegen die Sozialdemokratie» hervor, der in den folgenden zehn Jahren allerlei Flugschriften in einer Gesamtauflage von 47 Mio. Stück produzierte. ${ }^{58}$ Die Propagandaschriften des Verbandes attackierten die Sozialdemokraten einerseits als politische Gefahr, als reichsfeindliche "vaterlandslose Gesellen«, andererseits wurden sie moralisch diskreditiert. Schnöder Materialismus und "freie Liebe» wurden angeprangert, die Sozialdemokraten würden "allen rohen Instinkten" und den "niederen Leidenschaften der Masse» frönen. Sie mobilisierten "vaterlandsloses, gewalttätiges, glaubensloses, unzufriedenes und begehrliches Gesindel «. ${ }^{59}$ Wenn die Sozialdemokratie zur Herrschaft gekommen sei, drohe ein »Massenmord gegen alle Andersgesinnten" und die Reichen würden "abgeschlachtet «. ${ }^{60}$ Diese wüste Hetze versuchte noch einmal, den älteren Pöbel-Diskurs zu mobilisieren, um die politische Arbeiterbewegung aus der nationalen Gemeinschaft auszugrenzen. Die reformistisch gewordene Sozialdemokratie setzte dagegen ihre Respektabilitätsansprüche, ihre Parteidisziplin und ihre Wahlerfolge.

57 Sobich, Bestien, S. 156.

58 Ebd. S. 165.

59 Ebd. S. 168.

60 Zitiert nach ebd., S. 170. Vgl. auch Saul, Der Staat und die »Mächte des Umsturzes». 
